\title{
Depth-pressure relationships in the oceans and seas
}

\author{
Claude C. Leroy \\ Private consultant, Cabinet d'Etudes en Acoustique Sous-Marine, 41 rue du Docteur Clément, \\ 83330 Le Plan du Castellet, France \\ François Parthiot \\ Chief of Department of Underwater systems at GENAVIR, IFREMER, B.P. 330, 83507 La Seyne-sur-Mer \\ Cedex, France
}

(Received 28 March 1997; accepted for publication 21 November 1997)

\begin{abstract}
Two sets of equations, covering all world oceans and seas, are presented to calculate pressure from depth for the computation of sound speed, and depth from pressure for use in ocean engineering. They are based on the algorithm of UNESCO 1983 [N. P. Fofonoff and R. C. Millard, Jr., Unesco Tech. Papers in Mar. Sci. No. 44 (1983)], and on calculations from temperature and salinity profiles. The pressure to depth conversion is presented first. The equations can be used in those cases where the desired accuracy is reduced to $\pm 0.8 \mathrm{~m}$. The equations to convert depth to pressure provide an overall accuracy between $\pm 8000 \mathrm{~Pa}$ and $\pm 1000 \mathrm{~Pa}$. This leads to errors in sound speed consistently smaller than $\pm 0.02 \mathrm{~m} / \mathrm{s}$. The discussion, and comparisons with results and other formulas, suggest that the new equations are a substantial improvement on the previous simplified ones, which should now be abandoned. (C) 1998 Acoustical Society of America. [S0001-4966(98)02103-1]
\end{abstract}

PACS numbers: 43.30.Pc, 43.30.Es [DLB]

\section{INTRODUCTION}

The need to obtain pressure at sea from depth and location is found in many applications of underwater acoustics. The main topic is sound propagation, which depends on the variation of the speed of sound with depth and range. As the local speed of sound in the ocean varies with temperature $T$, salinity $S$, and pressure $P$, and because the precise laboratory measurements leading to the equations for the speed of sound were made in conditions where pressure was the measured parameter, the basic equations use pressure and not depth. Depth, however, must be used in the various calculations of sound propagation such as based on ray theory, etc. The temperature and salinity profiles in the sea are often obtained from in situ measurements that can be made as a function of depth or pressure, completed at great depth by values from data banks. Most of these, like that of Levitus ${ }^{1}$ for instance, and atlases, give $T$ and $S$ as a function of depth, not pressure. In all, for a specific sound propagation calculation, the user is mostly faced with the problem of converting depth into pressure for the calculation of sound speed. For this reason several simple formulas have been proposed. ${ }^{2-5}$ Their accuracy was limited to a final precision of \pm 0.5 to \pm 1 $\mathrm{m} / \mathrm{s}$ on sound speed, which was regarded as satisfactory up to ten years ago. This is no longer the case, especially in acoustic tomography, and an improvement by a factor of 10 is desirable. The reverse problem, that of pressure to depth conversion, has received considerable attention from oceanographers. The desired accuracy is indeed very high for such problems as the calculation of the motions of water masses, internal waves, etc. The procedure developed by Fofonoff and Millard ${ }^{6}$ (UNESCO 83), here usually abbreviated as F-M or U83, is well adapted to the problem of calculating depth $Z$ from pressure $P$, and a modest PC can easily handle the calculations once the specific program has been loaded. One must, however, enter $T(P)$ and $S(P)$ profiles by a number of layers with constant values, the sampling depending on the profiles and on the final desired accuracy.

A need arose three years ago at IFREMER to develop a simple method for calculating in real time the depth of a ROV or a deep towed fish down to $6000 \mathrm{~m}$ to an accuracy within only $\pm 1 \mathrm{~m}$, from a pressure gauge installed on the vehicle. It was decided to perform the complete oceanographic calculation with a number of selected $T$ and $S$ profiles covering the oceans and seas worldwide, and to determine from the results whether a limited number of simple equations applicable to very large areas could give depth within this accuracy from pressure and latitude only. This study, carried out by the authors, concluded that a single equation could account for $80 \%$ of worldwide conditions with an accuracy better than $\pm 0.8 \mathrm{~m}$. A set of ten alternative corrective terms could be developed for the other areas, especially the closed basins, with an accuracy of better than $\pm 0.2 \mathrm{~m}$ in most cases. The success of this procedure encouraged Leroy to attempt to develop equations for the reverse problem, the $Z$ to $P$ transformation, for which he had proposed an equation in $1968 .^{2}$ It was found that a single equation could cover most of the world with an accuracy better than $\pm 8000 \mathrm{~Pa}$, leading for sound speed to errors smaller than $\pm 0.02 \mathrm{~m} / \mathrm{s}$. A set of ten different corrective terms, for the same areas as considered in the $P$ to $Z$ transformation, was developed, providing an accuracy of the order of \pm 2000 $\mathrm{Pa}$. All of these figures are stated on the assumption that the U83 algorithm to convert $P$ into $Z$ is correct. Both results are presented here, starting briefly with the simplified $P$ to $Z$ transformation.

\section{CONVERSION OF PRESSURE INTO DEPTH}

According to Fofonoff and Millard, ${ }^{6}$ the depth $Z$ in the ocean is obtained from pressure and latitude by the equation: 


$$
Z=Z_{s}(P, \phi)+\frac{\Delta D}{9.8},
$$

which is obtained by solving the hydrostatic equation

$$
\int_{0}^{Z} g z \phi d Z=\int_{0}^{P} V_{T S P} d P .
$$

Here, $Z_{s}(P, \phi)$ is a universal expression giving depth in what is called by oceanographers the "standard ocean" (an ideal medium in temperature and salinity with $T=0{ }^{\circ} \mathrm{C}$ and $S$ $=35 \%$ o). The term $D$, called the geopotential anomaly, accounts for the difference in temperature and salinity structure from the standard ocean.

The complete formulation of F-M for $Z_{s}(P, \phi)$ reads, when $P$ is expressed in megaPascal (MPa) instead of decibar:

$$
Z_{s}=\frac{9.72659 \times 10^{2} P-2.512 \times 10^{-1} P^{2}+2.279 \times 10^{-4} P^{3}-1.82 \times 10^{-7} P^{4}}{g(\phi)+1.092 \times 10^{-4} P},
$$

where $g(\phi)$ is given by the international formula for gravity

$$
g(\phi)=9.780318\left(1+5.2788 \times 10^{-3} \sin ^{2} \phi-2.36 \times 10^{-5} \sin ^{4} \phi\right) .
$$

Although any personal computer can easily handle such calculations, it can be of interest to note that the following simplified formulation gives departures smaller than $\pm 0.03 \mathrm{~m}$ in all situations:

$$
Z_{s}(P, \phi)=\frac{9.7266 \times 10^{2} P-2.512 \times 10^{-1} P^{2}+2.28 \times 10^{-4} P^{3}-1.8 \times 10^{-7} P^{4}}{9.7803\left(1+5.3 \times 10^{-3} \sin ^{2} \phi\right)+1.1 \times 10^{-4} P} .
$$

This formula was used in the deep vehicle localization problem, where the final accuracy desired was only $\pm 1 \mathrm{~m}$.

We shall call corrective term proper to an area $i$ the quantity $\delta f_{i}=\Delta D / 9.8$, and rewrite Eq. (1) as

$$
Z=f(P, \phi)+\delta f i(Z)
$$

with $f(P, \phi) \equiv Z_{s}(P, \phi)$, given by Eqs. (3) plus (4) or Eq. (5).

The geopotential anomaly is given through $\Delta D$ $=\int_{0}^{P} \delta(T, S, P) d P$. The order $T, S, P$ has been chosen in place of the more usual $S, T, P$, in order to be consistent with the common use in underwater acoustics and in data banks for temperature and salinity. In practice, the integral for $\Delta D$ is replaced by a summation over a number of layers where the quantity $\delta$, called the specific volume anomaly, is considered to be constant. $\delta(T S, P)$ is given by: $\delta(T, S, P)$ $=V(T, S, P)-V(0,35, P)$ where $V$ is specific volume.

The method of calculating $\delta(T, S, P)$ is fully explained in Ref. 6, Part 3 and will not be repeated here. We mention only that the algorithm contains polynomial developments that use 45 coefficients and constants, each with 4-9 significant figures. This method has been programmed and applied with a number of $T$ and $S$ profiles covering the world oceans. Various questions had to be examined regarding the justification for using smoothed profiles such as those given by data banks like that of Levitus ${ }^{1}$ or oceanographic atlases, the effect of sampling, that of seasonal variations, etc. The first problem to solve was the transformation of the profiles given in depth into profiles in pressure. This was done by using the simplified equation of the form $P=P(Z, \phi)$ proposed in 1978 by Lovett. ${ }^{3}$ The use of this equation was preferred to that of Leroy ${ }^{2}$ after a preliminary investigation. It was then found, for the purpose of achieving an accuracy "better than $\pm 1 \mathrm{~m}$," that the sampling used in Levitus ${ }^{1}$ (with $Z$ transformed into $P$ ) was totally satisfactory: the difference be- tween the values of $Z$ obtained when using this sampling, and those obtained from various enriched profiles, derived from the original one by inserting points through interpolations on fourth degree Newton polynomials, was smaller than $\pm 0.05 \mathrm{~m}$. As for the seasonal variations and the smoothing (comparison with the use of detailed measured profiles), these never led to errors greater than $\pm 0.1 \mathrm{~m}$ at depth in the worst cases.

The results of the study in the open oceans are expressed by the equation

$$
\delta f_{0}(P)=P /(P+1)+5.7 \times 10^{-2} P .
$$

This equation was found to represent all open oceans situations within better than $\pm 0.8 \mathrm{~m}$ with two exceptions: (i) the North Eastern Atlantic area between $30^{\circ}$ and $35^{\circ} \mathrm{N}$, for which a separate equation $\delta f_{1}(P)$ is given in Table I, and (ii) circumpolar waters around the Antarctic. In that case, another equation $\delta f_{2}(P)$, also given in Table I, was found to give an accuracy better than $\pm 0.01 \mathrm{~m}$ at various places for latitudes higher than $50^{\circ} \mathrm{S}$. However, the intermediate waters between the Antarctic ones and the common South Atlantic, Indian, and Pacific Oceans cannot be described with one single equation, and this is a unique particular case.

All closed basins were subsequently examined sytematically, and a total set of 9 further simple equations for $\delta f_{i}(P)$ was found capable of covering all of them, with an accuracy better than $\pm 0.2 \mathrm{~m}$ in most cases. All of these equations are presented in Table I. More comments about those basins will be given in the next chapter when considering the depth to pressure conversion.

\section{CONVERSION OF DEPTH INTO PRESSURE}

Since it was found in the study of the pressure to depth conversion by simple formulas that solutions of the form of Eq. (6) could give accuracies from \pm 0.8 to $\pm 0.1 \mathrm{~m}$, it was 
TABLE I. Corrective terms $\delta f_{i}(P)$ to be added to Eqs. (3)-(4) or Eq. (5) for obtaining depth $Z$ (in $\left.\mathrm{m}\right)$ from pressure $P$ (in $\mathrm{MPa}$ ) in the various areas of the world.

\begin{tabular}{|c|c|c|c|c|}
\hline No. & Area of applicability & Latitude & Expression for $\delta f_{i}(P)$ & Accuracy $( \pm m)$ \\
\hline 0 & $\begin{array}{c}\text { Common oceans between } \\
60^{\circ} \mathrm{N} \text { and } 40^{\circ} \mathrm{S}\end{array}$ & $\begin{array}{c}\text { as } \\
\text { appropriate }\end{array}$ & $P /(P+1)+5.7 \times 10^{-2} P$ & 0.8 \\
\hline 1 & North Eastern Atlantic & id $\left(30-35^{\circ}\right)$ & $P /(P+2)+3 \times 10^{-2} P$ & 0.3 \\
\hline 2 & $\begin{array}{c}\text { Circumpolar Antarctic } \\
\text { waters }\end{array}$ & as & $4 \times 10^{-2} P-2 \times 10^{-4} P^{2}$ & 0.1 \\
\hline 3 & Mediterranean Sea & id & $-7 \times 10^{-2} P+2 \times 10^{-3} P^{2}$ & 0.2 \\
\hline 4 & Red Sea & id & None & 0.2 \\
\hline 5 & Arctic ocean & id & None & 0.1 \\
\hline 6 & Sea of Japan & id & $\begin{array}{l}\text { (a) } 6 \times 10^{-2} P \\
\text { (b) } \delta f_{0}(P)\end{array}$ & $\begin{array}{l}0.1 \\
0.8\end{array}$ \\
\hline 7 & Sulu Sea & $8^{\circ}$ & $\begin{array}{c}0.9 P /(P+1)+0.17 P \\
+7 \times 10^{-4} P^{2}\end{array}$ & 0.2 \\
\hline 8 & Halmahera basin & $0^{\circ}$ & $0.8 P /(P+0.5)+0.125 P$ & 0.1 \\
\hline 9 & $\begin{array}{l}\text { Celebes basin } \\
\text { Weber deep }\end{array}$ & $\begin{array}{l}4^{\circ} \\
6^{\circ}\end{array}$ & $\begin{array}{c}1.2 P /(P+1)+6.7 \times 10^{-2} P \\
+2.2 \times 10^{-4} P^{2}\end{array}$ & 0.4 \\
\hline 10 & Black Sea & $43^{\circ}$ & $1.1 P$ & 0.1 \\
\hline 11 & Baltic Sea & $60^{\circ}$ & $1.8 P$ & 0.1 \\
\hline
\end{tabular}

though that corresponding accuracies, viz., always better than $\pm 8000 \mathrm{~Pa}$, could be obtained by reversing the $P$ to $Z$ algorithm.

A global reversal of Eq. (6) was judged inappropriate because it would have led to a formulation with corrective terms to be applied prior to use the equation reversing that for depth in the standard ocean. Instead, solutions of the form $P_{i}(Z, \phi)=h(Z, \phi)-\delta h_{i}(Z)[h(Z, \phi)$ reversing $f(P, \phi)$ and $\delta h_{i}$ being positive] were sought. It was obvious from the previous study that these corrective terms would follow the same geographical distribution as the $\delta f_{i}$ of Table I.

The inversion of the equation giving $Z$ from $P$ and $\phi$ in the standard ocean [Eq. (2) plus (3) from F-M] was carried out by calculating a fourth degree Newton polynomial joining $5(P, Z)$ doublets for latitude $45^{\circ}$, with $Z$ between 0 and $8000 \mathrm{~m}$. This provided an equation for $h(Z, 45)$, whose coefficients were simplified by trial and error until an acceptable form was found to fit the whole range $0-11000 \mathrm{~m}$. To account for latitude, intuition suggested a form $h(Z, \phi)$ $=h(Z, 45) \times(g(\phi)-a Z) /(g(45)-a Z)$. It was considered that the use of the complete equation for gravity was not necessary and that a simpler one like in Eq. (5) could be sufficient. Finally, the following equation was adopted.

$$
h(Z, \phi)=h(Z, 45) \times k(Z, \phi),
$$

with, $Z$ being in meters and $P$ in megaPascal,

$$
\begin{aligned}
h(Z, 45)= & 1.00818 \times 10^{-2} Z+2.465 \times 10^{-8} Z^{2}-1.25 \\
& \times 10^{-13} Z^{3}+2.8 \times 10^{-19} Z^{4}, \\
k(Z, \phi)= & \left(g(\phi)-2 \times 10^{-5} Z\right) /\left(9.80612-2 \times 10^{-5} Z\right), \\
g(\phi)= & 0.7803\left(1+5.3 \times 10^{-3} \sin ^{2} \phi\right) .
\end{aligned}
$$

The accuracy of Eqs. (8)-(11) was checked to be within $\pm 500 \mathrm{~Pa}$ over the entire range of possibilities for depth and latitude by systematic computer calculations. Depth was calculated from pressure using the complete formulation given by Eqs. (3) plus (4), and pressure calculated back from the obtained depth through Eqs. (8)-(11).
The calculation of the various corrective terms was performed by an iterative process in order to ensure maximum accuracy.

In the open oceans between latitudes $60^{\circ} \mathrm{N}$ and $40^{\circ} \mathrm{S}$ one single corrective term can be adopted, which reads

$$
\delta h_{0}(Z)=0.8 Z /(Z+100)+6.2 \times 10^{-6} Z \text {. }
$$

The other corrective terms are given in Table II.

Figure 1 gives the results for the open oceans. The investigation was extended to the greatest depths and not limited to $8000 \mathrm{~m}$ as in the ROV problem. Figure 2 gives the results for the closed basins. Figure 2(a) is drawn with the same horizontal scale as Fig. 1, with the three curves corresponding to the common open oceans for comparison. The correction for the Sea of Japan remains within the $\pm 8000 \mathrm{~Pa}$ of Eq. (12), but the separate more precise equation given in Table II can be used if desired. The Arctic Ocean and the Red Sea do not require corrective terms, the former because its characteristics are close to those of the standard ocean, and the latter because it is not deep enough for the geopotential anomaly to be significant. For the Mediterranean, the corrective term has a different sign from the others, and a second degree equation is needed for accuracy. Figure 2(b), drawn with a different scale, presents the results for Indonesian closed basins. These are very numerous and information about them may be found for example in Ref. 7. It was found, as in the reverse problem, that except for the basins specifically mentioned in Fig. 2(b) and Table II, the corrective terms can be approximated by Eq. (12). The Sulu Sea needs a quite different correction, as already pointed out by Lovett ${ }^{3}$ who claimed that it as the third most irregular case in the world, after the Baltic and the Black Sea. These two last exceptional cases, with low-saline water, are illustrated in Fig. 2(c), with again a different scale. 
TABLE II. Corrective terms $\delta h_{i}(Z)$ to be subtracted from the values given by Eqs. (8)-(11) for obtaining pressure $P$ (in $\mathrm{MPa}$ ) from depth $Z$ (in $\mathrm{m}$ ) in the various areas of the world.

\begin{tabular}{|c|c|c|c|c|}
\hline No. & Area of applicability & Latitude & Expression for $\delta h_{i}(Z)$ & $\begin{array}{l}\text { Accuracy } \\
\left( \pm 10^{3} \mathrm{~Pa}\right)\end{array}$ \\
\hline 0 & $\begin{array}{l}\text { Common oceans between } \\
60^{\circ} \mathrm{N} \text { and } 40^{\circ} \mathrm{S}\end{array}$ & $\begin{array}{l}\text { as } \\
\text { appropriate }\end{array}$ & $1.0 \times 10^{-2} Z /(Z+100)+6.2 \times 10^{-6} Z$ & 8 \\
\hline 1 & North Eastern Atlantic & id $\left(30-35^{\circ}\right)$ & $8 \times 10^{-3} Z /(Z+200)+4.0 \times 10^{-6} Z$ & 3 \\
\hline 2 & $\begin{array}{c}\text { Circumpolar Antarctic } \\
\text { waters }\end{array}$ & $\begin{array}{l}\text { as } \\
\text { appropriate }\end{array}$ & $8 \times 10^{-3} Z /(Z+1000)+1.6 \times 10^{-6} Z$ & 1 \\
\hline 3 & Mediterranean Sea & id & $-8.5 \times 10^{-6} Z+1.4 \times 10^{-9} Z^{2}$ & 2 \\
\hline 4 & Red Sea & id & None & 2 \\
\hline 5 & Arctic Ocean & id & None & 1 \\
\hline \multirow[t]{2}{*}{6} & Sea of Japan & id & (a) $7.8 \times 10^{-6} Z$ & 1 \\
\hline & & & (b) $\delta h_{0}(Z)$ & 8 \\
\hline 7 & Sulu Sea & $8^{\circ}$ & $\begin{array}{c}1.0 \times 10^{-2} Z /(Z+100)+1.6 \times 10^{-5} Z \\
+1.0 \times 10^{-9} Z^{2}\end{array}$ & $<1$ \\
\hline 8 & Halmahera basin & $0^{\circ}$ & $8 \times 10^{-3} Z /(Z+50)+1.3 \times 10^{-5} Z$ & $<1$ \\
\hline \multirow[t]{2}{*}{9} & Celebes basin & $4^{\circ}$ & $1.2 \times 10^{-2} Z /(Z+100)+7.0 \times 10^{-6} Z$ & 2 \\
\hline & Weber deep & $6^{\circ}$ & $+2.5 \times 10^{-10} Z^{2}$ & \\
\hline 10 & Black Sea & $43^{\circ}$ & $1.13 \times 10^{-4} Z$ & 1 \\
\hline 11 & Baltic Sea & $60^{\circ}$ & $1.8 \times 10^{-4} Z$ & 1 \\
\hline
\end{tabular}

\section{DISCUSSION}

\section{A. Pressure to depth conversion}

A simple formulation giving depth as a function of pressure and latitude was given in the instruction manual of Bisset-Berman. ${ }^{8}$ It reads

$$
Z=\frac{9.7512 P}{1+5.3 \times 10^{-3} \sin ^{2} \phi}-2.07 \times 10^{-4} P^{2}
$$

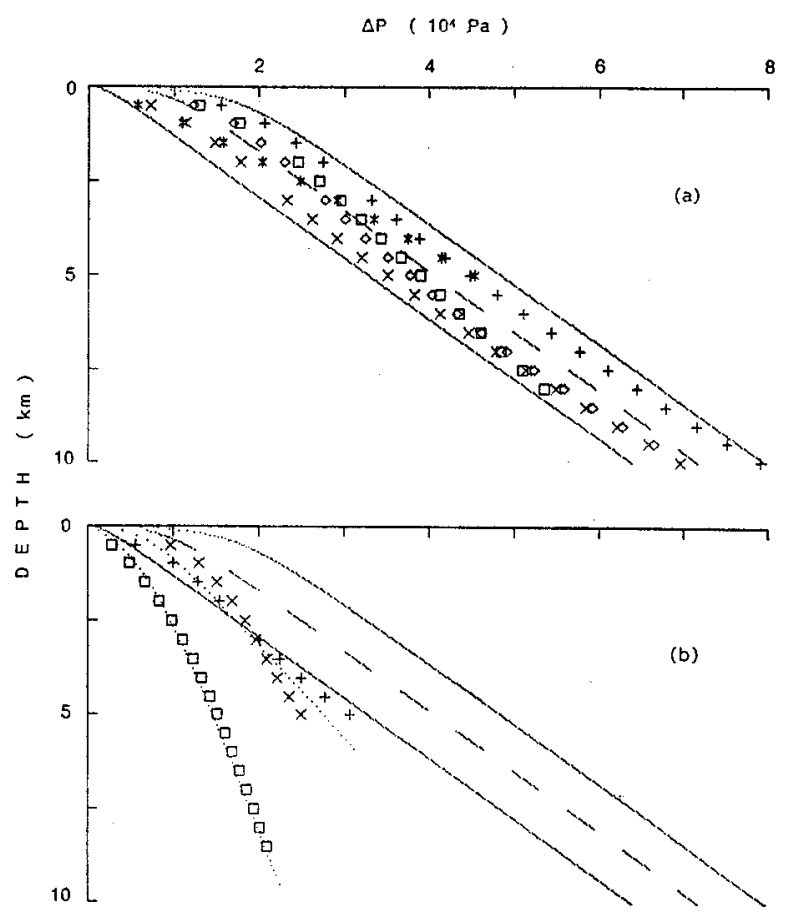

FIG. 1. Pressure corrections $\Delta P=\delta h_{i}(Z)$ to be subtracted from $h(Z, \phi)$ as given by Eqs. (8) -(11) to account for the geopotential anomalies. (a) Main oceans: + Pacific (Marianna trench); $\times$ Pacific (Kouril trench); * North Atlantic (Puerto Rico trench); $\diamond$ South Atlantic; $\square$ Indian Ocean. (b) Special cases: + and $\times$ North-East Atlantic; $\square$ Antarctic circumpolar water. with $Z$ in $\mathrm{m}$ and $P$ in $\mathrm{kg} / \mathrm{cm}^{2}$ above atmospheric. The results obtained from this equation are higher by $+0.1-+4 \mathrm{~m}$ than those given by Eqs. (8)-(11) without the corrective term, i.e., for the standard ocean. If the Bisset-Berman equation is considered to be applicable to the real common oceans, then it gives results that are lower than Eqs. (8)-(11) completed by the corrective term given in Eq. (12), the difference lying between -1 to $-4.5 \mathrm{~m}$.

As more simplified equations to calculate pressure $P$ from depth $Z$ have been proposed, useful comparisons can be made by examining the reverse problem.

\section{B. Depth to pressure conversion}

The conversion of depth to pressure has been the subject of several publications. The first simple equation seems to have been proposed by Leroy ${ }^{2}$ in 1968, for the purpose of calculating sound speed. The basic equation was applicable to the main oceans and reads for pressure above atmospheric:

$$
\begin{aligned}
P= & 0.102506\left(1+5.28 \times 10^{-3} \sin ^{2} \phi\right) Z+2.524 \\
& \times 10^{-7} Z^{2}
\end{aligned}
$$

with $P$ in $\mathrm{kg} / \mathrm{cm}^{2}$. Simple modified versions without the gravity term were proposed for the Black Sea and the Baltic Sea (the Sulu Sea had been forgotten). The development of these equations was carried out by solving

$$
P=\int_{0}^{Z} \rho_{T S Z} g_{Z \phi} d Z
$$

with linear approximations of $\rho_{T S Z}$ and $g_{\phi Z}$. The first one was adjusted from graphs by Bialek ${ }^{9}$ and a modified expression of gravity versus depth was used for the second. The resulting second degree expression in $Z$ was integrated in closed form, with a third degree term that could be neglected.

Ten years later, in an attempt to revise the Del Grosso's ${ }^{10}$ NRL II equation for the speed of sound in sea water, Lovett proposed for calculating pressure what he 


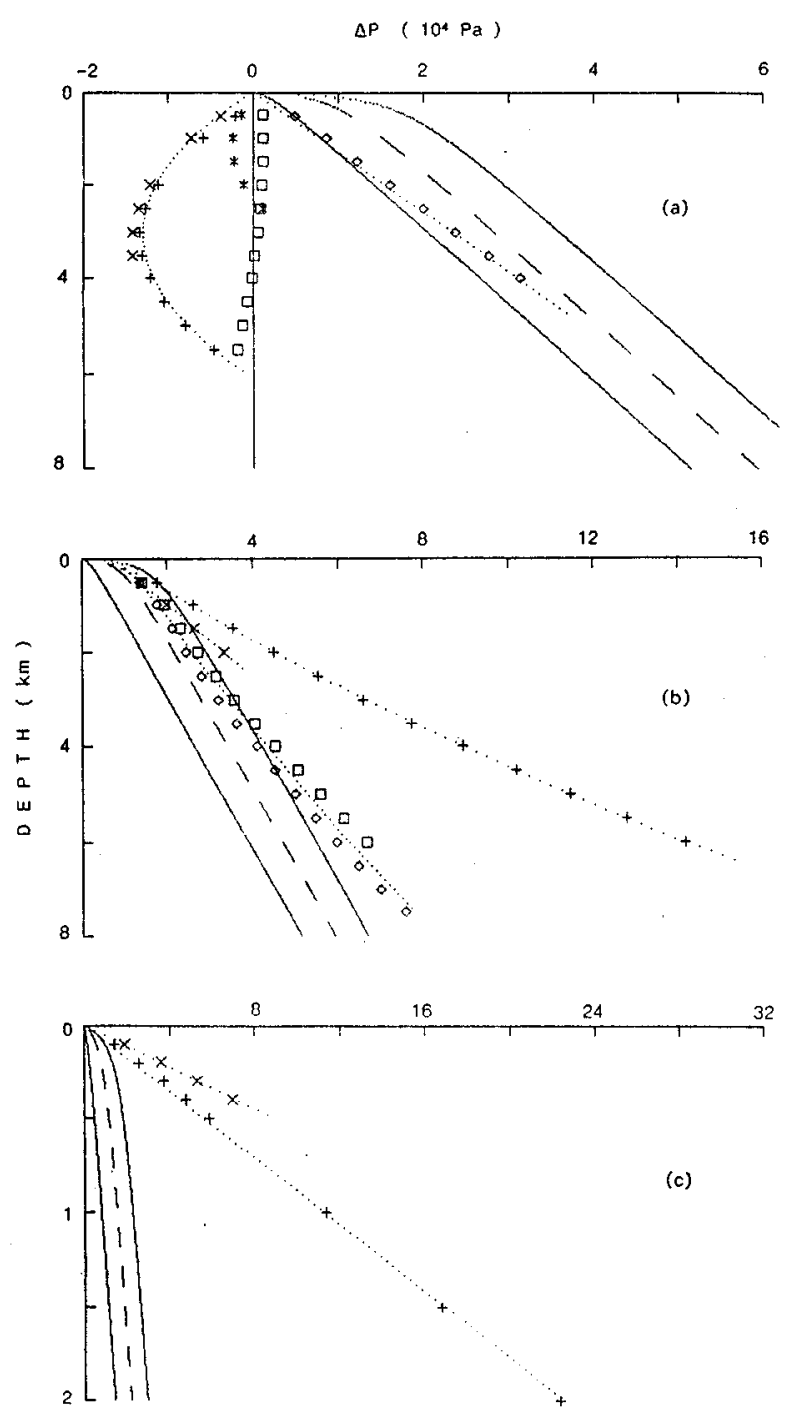

FIG. 2. Pressure corrections $\Delta P=\delta h_{i}(Z)$ to be subtracted from $h(Z, \phi)$ to account for the geopotential anomalies in the closed basins. (a) Miscellaneous: + Mediterranean Sea; $\times$ Red Sea; $\diamond$ Sea of Japan; $\square$ Arctic Ocean. (b) Indonesian basins: + Sulu Sea; $\times$ Halmahera basin; $\diamond$ Weber deep; $\square$ Celebes basin. (c) Low saline basins: + Black Sea; $\times$ Baltic Sea.

called a "modified version of Leroy's simplified equation", (Ref. 3, p. 1716). This reads, with $P$ in dbar:

$$
\begin{aligned}
P= & 1.0052405\left(1+5.28 \times 10^{-3} \sin ^{2} \phi\right) Z+2.36 \\
& \times 10^{-6} Z^{2} .
\end{aligned}
$$

The conversion of Leroy's equation to use dbar instead of $\mathrm{kg} / \mathrm{cm}^{2}$ gives, in fact, exactly the same figures for the first degree term, and only the coefficient of the second degree term is different $\left(2.475 \times 10^{-6}\right.$ instead of $\left.2.36 \times 10^{-6}\right)$.

In a paper published in 1981 Mackenzie $^{11}$ pointed out that most authors of publications about sound propagation did not mention the method they had employed to obtain pressure from depth in the unavoidable calculation of sound speed. He himself did not propose equations but employed a development that had long been used by oceanographers ${ }^{12-14}$ based upon the resolution of Eq. (14) by summation over homogeneous layers. This method is summarized in Appen-

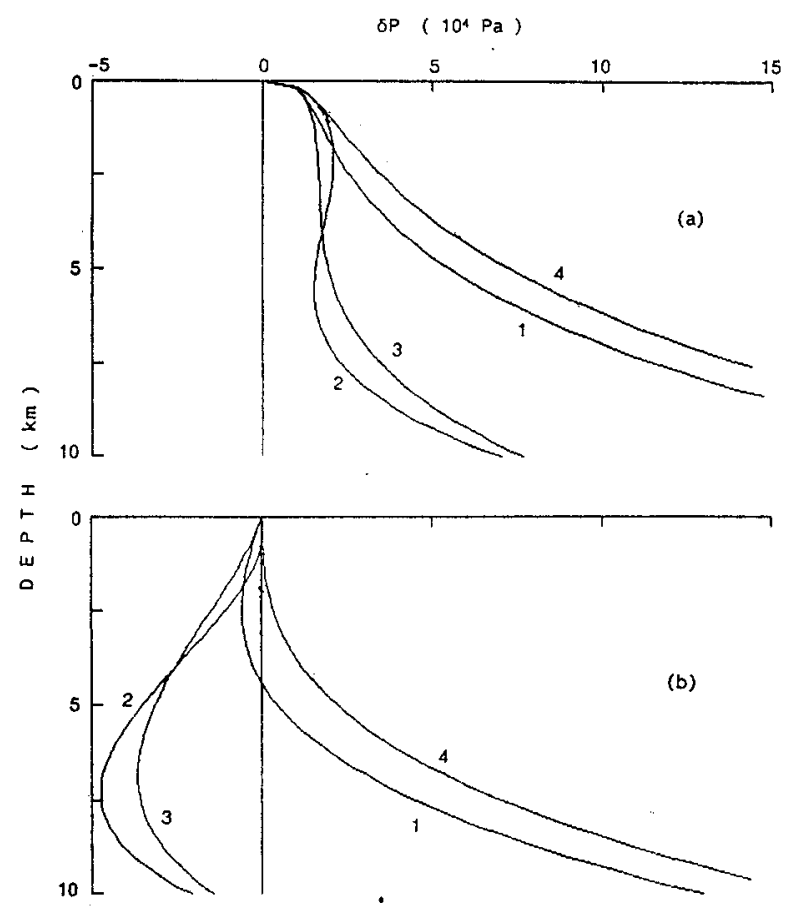

FIG. 3. Differences $\delta P$ between pressure given by various equations and the present one [Eqs. (8)-(11)]. (a) With the corrective term for common oceans. (b) Without the corrective term. 1-Leroy 1968 (Ref. 2); 2-BissetBerman inverted (Ref. 8); 3-Lovett (Ref. 3); 4-Siess (Ref. 4).

dix A of Ref. 11, which gives all the necessary coefficients, but requires the introduction of $T$ and $S$ profiles.

A simplified equation to calculate pressure from depth and latitude was presented in 1982 by $\mathrm{Siess}^{4}$ in an unpublished communication. With $P$ in dbar it reads:

$$
P=1.0082 Z\left(1-2.64 \times 10^{-3} \cos 2 \phi+2.45 \times 10^{-6} Z\right) .
$$

This equation in fact concerns the standard ocean, but Siess had compared it with that of Leroy for the common oceans. Purely by accident these two equations do not much differ once Leroy's is reformulated to use decibars and $\cos 2 \phi$ instead of $\sin ^{2} \phi$. This is why Leroy, in a review of sound speed in "Neptunian", waters written in 1988, ${ }^{5}$ adopted without further investigation a compromise between his 1968 equation and that of Siess. It reads, with $P$ in dbar:

$$
P=1.008 Z\left(1-2.64 \times 10^{-3} \cos 2 \phi+2.45 \times 10^{-6} Z\right)
$$

which, for comparison with Eq. (15), can be reformulated as

$$
\begin{aligned}
P= & 1.00534\left(1+5.294 \times 10^{-3} \sin ^{2} \phi\right) Z+2.46 \\
& \times 10^{-6} Z^{2} .
\end{aligned}
$$

\section{Comparison of the results}

The difference $\delta P$ between the pressure calculated by the present Eqs. (8)-(11) taken as the reference, and those obtained from the equations of Leroy (1968), Lovett, BissetBerman (inverted), and Siess are illustrated in Fig. 3 for a latitude of $45^{\circ}$. Figure $3(\mathrm{a})$ corresponds to the common oceans situation, with the corrective term of Eq. (12). Figure 3(b) gives the differences obtained when Eqs. (8)-(11) are 
applied without the corrective term, i.e., for the standard ocean. One can observe that there exists a definite discrepancy between the new equation and the simplified previous ones, in particular those of Leroy and Siess. This deserved more investigation.

We found that Siess had carried out his mathematical development in small quantities up to the third degree in $Z$, but had deliberately neglected the last term in his numerical application because it gave an accuracy of $0.2 \%$ which was considered sufficient for the computation of sound speed. By calculating and adding this last term, and by using one more significant figure in the coefficients of the previous ones, the equation of Siess can be reformulated, with $P$ in dbar, as

$$
\begin{aligned}
P= & 1.00818 Z\left(1-2.64 \times 10^{-3} \cos 2 \phi+2.453 \times 10^{-6} Z\right. \\
& \left.-1.3 \times 10^{-11} Z^{2}\right) .
\end{aligned}
$$

The results given by this modified equation are in much better agreement with those of our present equations [Eqs. (8)-(11)] for the standard ocean: the maximum differences between the calculated pressures are reduced from 1.4 $\times 10^{5} \mathrm{~Pa}$ to $\pm 2 \times 10^{3} \mathrm{~Pa}$ only at depth for all latitudes. As for Leroy's 1968 equation (developed in greater detail in a SACLANTCEN Report, ${ }^{15}$ we discovered that its second degree term was extremely sensitive to the two simple linear aproximations used for density and gravity. The fit to the Bialek's data made in Ref. 2, Fig. 1, p. 652 reads, with density in $\mathrm{g} / \mathrm{cm}^{8}: \rho(Z)=1.00274+2.4 \times 10^{-6} Z$. If we adopt instead the law $\rho(Z)=1.0028+2.3 \times 10^{-6} Z$, not much difference can be seen of the figure! If, in addition, we use for the gradient of gravity with depth the classical value 2.2 $\times 10^{-6}$ (instead of $2.4 \times 10^{-6}$ ) the second degree term of Leroy, for $P$ in dbar, becomes $2.367 \times 10^{-6} \mathrm{Z}$, which differs from the original formulation $\left(2.475 \times 10^{-6} Z\right.$ as seen above), and is much closer to that adopted by Lovett in Eq. (15). In all, we can conclude that the disagreements between the present equations and the original equations of Leroy and Siess are now fully explained.

To improve the motivation for publishing the present discussion we have compared our results with the various data presented by Mackenzie in his 1981 publication. ${ }^{11}$ In Table AI, page 810, values of pressure versus depth in the Marianna trench are given down to $10916 \mathrm{~m}$. Equations (8)(11) used with the common ocean corrective term gives, after transformation for units, the same values within $\pm 0.05 \mathrm{~kg} / \mathrm{cm}^{2}$. Table I, page 809 in the same reference, presents a set of data from 15 locations covering the world, used by Mackenzie to establish the average variation of pressure with depth for building his proposed equation for sound speed. In this case the data are values of depth as a function of pressure. They have been compared with the results obtained from Eqs. (5)-(7) presented in Chapter I for the reverse problem and found in good agreement (better than $\pm 0.9 \mathrm{~m}$ ), but with one exception: (Point C) south of Alaska, where an unexpected departure of $1.6 \mathrm{~m}$ is observed. As the $T$ and $S$ profiles used by Mackenzie were not given, and as his calculation was based on less recent algorithms the observe differences may be understandable.
A final comment needs to be made about the exactness of the data used in this development to assess the accuracy claimed. The first concerns the equation of state of sea water, which needs to be exact, and the second concerns the oceanographic data. On that subject, a question that could be raised is the transformation of pressure into depth when the original measurements used for establishing the data banks had used pressure. Was the $P$ to $Z$ conversion, including the latitude effect, properly made? It would be worth investigating this point, but we think, considering the intermediate steps of our computation, that the errors introduced would most probably be of second order. To summarize, the set of corrective terms $\delta h_{i}(Z)$ or $\delta f_{i}(P)$ should not suffer from substantial errors, and little improvement could be expected from further work. The main terms for the standard ocean could easily be modified if a new equation of state were proved to be significantly more accurate.

\section{CONCLUSION}

Based on the algorithm of Fofonoff and Millard (UNESCO 83), a simplified formulation for use in ocean engineering has been developed for converting pressure into depth in oceans and seas. Its general expression is:

$$
Z=f(P, \phi)+\delta f_{i}(P),
$$

where $f(P, \phi)$ stands for the standard ocean and $\delta f_{i}(P)$ is a simple corrective term applicable to a particular area. One main term can cover $80 \%$ of the world conditions, found in open oceans, with an accuracy better than $\pm 0.8 \mathrm{~m}$. Ten alternative terms are provided for special cases, including all closed basins, with accuracies better than $\pm 0.2 \mathrm{~m}$ in most applications. This method enables to calculate depth within always better than $\pm 1 \mathrm{~m}$ from pressure and latitude only, without having to perform XBT measurements or use data banks. The proper corrective term $\delta f_{i}(P)$ is selected according to the surveyed area.

Equations to obtain pressure from depth, for use in calculating sound speed, have been developed from the inversion of the $Z(P, \phi)$ equation for the standard ocean and calculations proper to the various areas studied in the previous section have been made. The general formulation is

$$
P=h(Z, \phi)-\delta h_{i}(Z),
$$

where $h(Z, \phi)$ is given by the set of equations [Eqs. (8)(11)] and the $\delta h_{i}(Z)$ are given by Table II. The equations provide worldwide coverage with overall accuracies between $\pm 500 \mathrm{~Pa}$ and $\pm 8000 \mathrm{~Pa}$. This corresponds to errors lower than $\pm 0.02 \mathrm{~m} / \mathrm{s}$ when calculating sound speed, which is appropriate with an accurate equation like that of Del Grosso. ${ }^{10}$ It is believed, under the assumption that the Fofonoff and Millard algorithm for calculating pressure is exact, that the previous simplified equations giving pressure versus depth, like Leroy's in particular and even Lovett's, should now be abandoned.

\section{ACKNOWLEDGMENTS}

The presentation of the pressure to depth conversion by simple equations was sponsored by IFREMER through its 
subsidiary GENAVIR. The work on the calculation of pressure from depth was supported by the LSM Department of the CTSN (DCN, French Navy, Toulon).

${ }^{1}$ S. Levitus, Climatological Atlas of the World Ocean, NOAA prof. Paper No. 13 (U.S. Government Printing Office, Washington, DC, 1982).

${ }^{2}$ C. C. Leroy, "Formulae for the calculation of underwater pressure in acoustics," J. Acoust. Soc. Am. 44, 651-653 (1968).

${ }^{3}$ J. R. Lovett, "Merged seawater sound-speed equations," J. Acoust. Soc. Am. 63, 1713-1718 (1978)

${ }^{4}$ IPA Siess, "Relation entre pression et immersion dans l'océan," (relationship between pressure and depth in the ocean), Annex to letter 293 EPSHOM/E/OC (1982) (in French).

${ }^{5}$ C. C. Leroy, "La vitesse du son dans les eaux neptuniennes-Synthèse et mise à jour" (Speed of sound in Neptunian waters-Review and updating), Consultant Report for CERDSM No. ACS 88/02/03 (1988) (in French).

${ }^{6}$ N. P. Fofonoff and R. C. Millard, Jr., "Algorithms for computation of fundamental properties of seawater," Unesco Tech. Papers in Mar. Sci., No. 44 (1983).

${ }^{7}$ H. U. Sverdrup, M. W. Johnson, and R. H. Fleming, "The water masses and currents in the oceans," in The Oceans-Their Physics, Chemistry, and General Biology (Prentice-Hall, Englewood Cliffs, NJ, 1942, reissued 1970), Chap. XV, pp. 735-738.

8 "Instruction manual for salinity/temperature/depth/sound velocity measuring systems models 9040"' (Bisset Berman, San Diego, CA, 1971)

${ }^{9}$ E. L. Bialek, "Handbook of oceanographic tables," U.S. Naval Ocean Office, SP-68 (1966).

${ }^{10} \mathrm{~V}$. A. Del Grosso, "New equation for the speed of sound in natural waters (with comparisons to other equations)," J. Acoust. Soc. Am. 56, 10841091 (1974)

${ }^{11} \mathrm{~K}$. V. Mackenzie, "Nine-term equation for sound speed in the oceans," J. Acoust. Soc. Am. 70, 807-812 (1981).

${ }^{12}$ N. P. Fofonoff and C. Froese, "Program for oceanographic computations and data processing on the electronic computer ALWAC III-E,' Fish. Res. Board of Canada, Rep. 25 (1958).

${ }^{13}$ N. P. Fofonoff and S. Sabata (same title as above), Fish. Res. Board of Canada, Rep. 27 (1958).

${ }^{14}$ H. E. Sweers, "A comparison of methods used to calculate sigma-T, specific volume anomaly and dynamic height," J. Marine Tech. Soc. 5, 7-26 (1971)

${ }^{15} \mathrm{C}$. C. Leroy, "A universal formula for the calculation of underwater pressure in acoustic studies," SACLANT ASW Research Centre Technical Report No. 108 (1968). 